\title{
THE GENII PRINT PHENOMENON
}

The tale of Genji (Genji monogatari; hereafter Genji) is perhaps the greatest work of classical Japanese literature and it is intimately known among aficionados of Japanese art. Almost every expert has something new to say about the novel's hero, Prince Genji, and many are fascinated by the pictorial depictions of the novel found in countless paintings; predominantly six-panel folding screens that are almost human-scale (fig. 1). It is less well known however, that the vast majority of the hundreds of Japanese woodblock prints that portray Genji are not in fact related to the classic tale at all, but rather to another Genji-inspired story that only emerged some 800 years later.

\section{The Genji Print Phenomenon}

The first instalment of the serial novel A rustic Genji by a fraudulent Murasaki (Nise Murasaki inaka Genji), written by Ryutei Tanehiko (1783-1842) and illustrated by the print designer Utagawa Kunisada (1786-1865) was published in 1829. A rustic Genji is an adaptation of Genji set in the 15th century. Mitsuuji, the Casanova-like hero, is modelled on Prince Genji. The storyline parallels the plot of the classic novel, but is delivered in the light and entertaining manner typical of late-Edo period popular fiction. The publisher Tsuruya Kiemon issued the story as a gokan, or serial novel, in 38 instalments over a period of 14 years, the last appearing in 1842 . The novel's popularity inspired print publishers and designers to use its protagonists and pivotal scenes as motifs for sheet prints, which further fuelled the vogue for $A$ rustic Genji, leading to the creation of sequels and, most importantly, a new genre in woodblock prints. ${ }^{1}$ Over a period of sixty years from the issue of the first Genji prints to the final flourish of the genre at the turn of the century, almost 1,300 designs were created with A rustic Genji as their motif. This Genji 'boom' was second to none in the centuries-long history of Japanese woodblock prints.

Around 1838, Kunisada created the first single-sheet prints based on A rustic Genji (fig. 2), as a series of 15 prints with the same title as the novel, A rustic Genji by a fraudulent Murasaki (Nise Murasaki inaka Genji). The publication coincided with the staging of the kabuki play Court style and Genji's Edopattern (Gosho moyo Genji no Edozome) in the third month of 1838 at the Ichimura Theatre, and Mitsuuji's facial features in the prints resemble those of the actor Ichimura Uzaemon XII (1812-51), who performed the main role.

\section{Prints Related to the Classical 'Genji'}

From the early 18th century, long before the launch of A rustic Genji, a small number of prints were published that relatedotorthedelassical Genjimeither2023 02:58: 04PM 


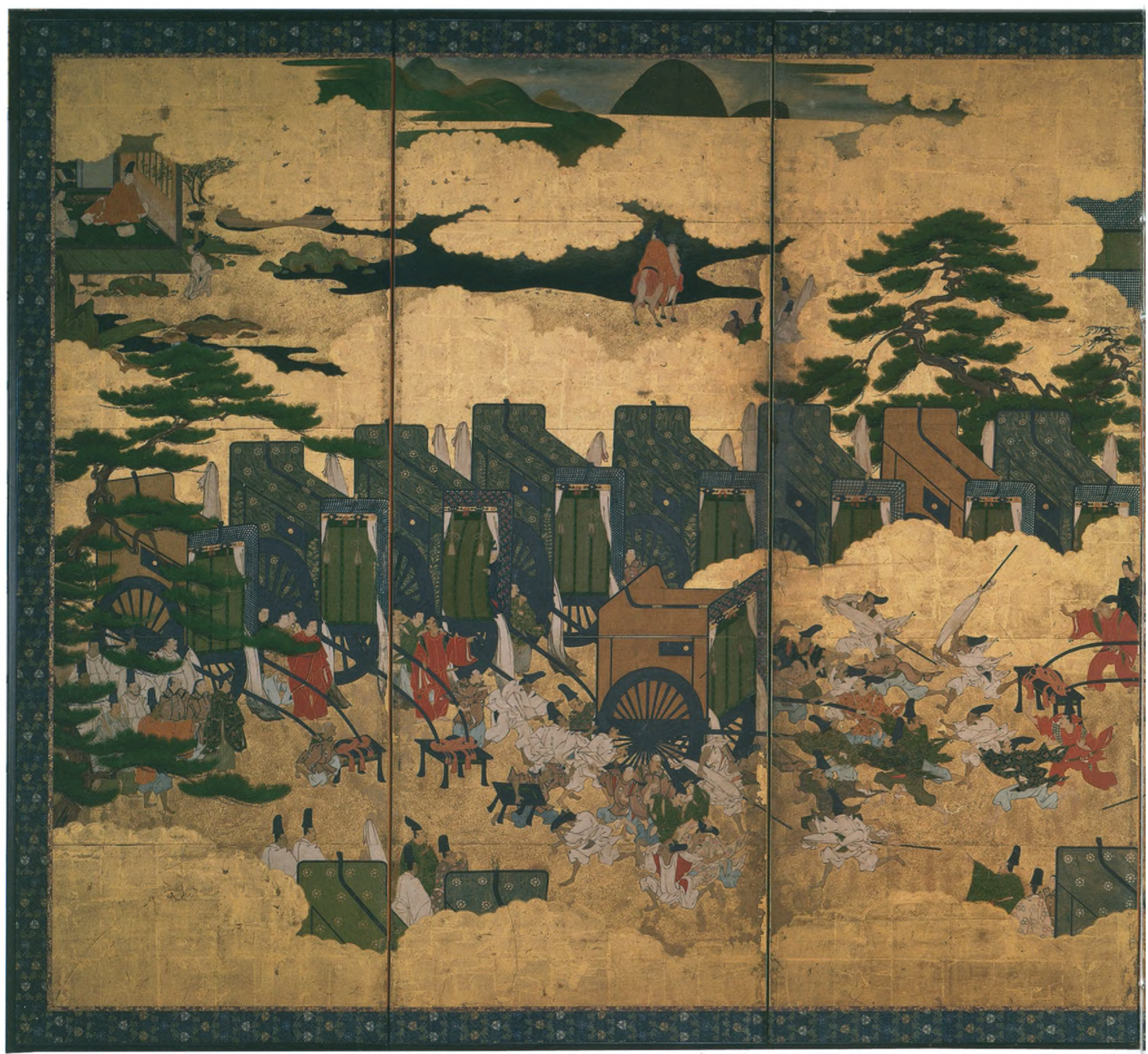

Figure 1

Unknown Tosa school

artist. Scenes from the

Tale of Genji in the Four

Seasons. Mid-17th

century. Six-panel

folding screen; right of a

pair. $157 \times 357 \mathrm{~cm}$. Ink

and colour on gold leaf.

Clark Center for

Japanese Art \& Culture 


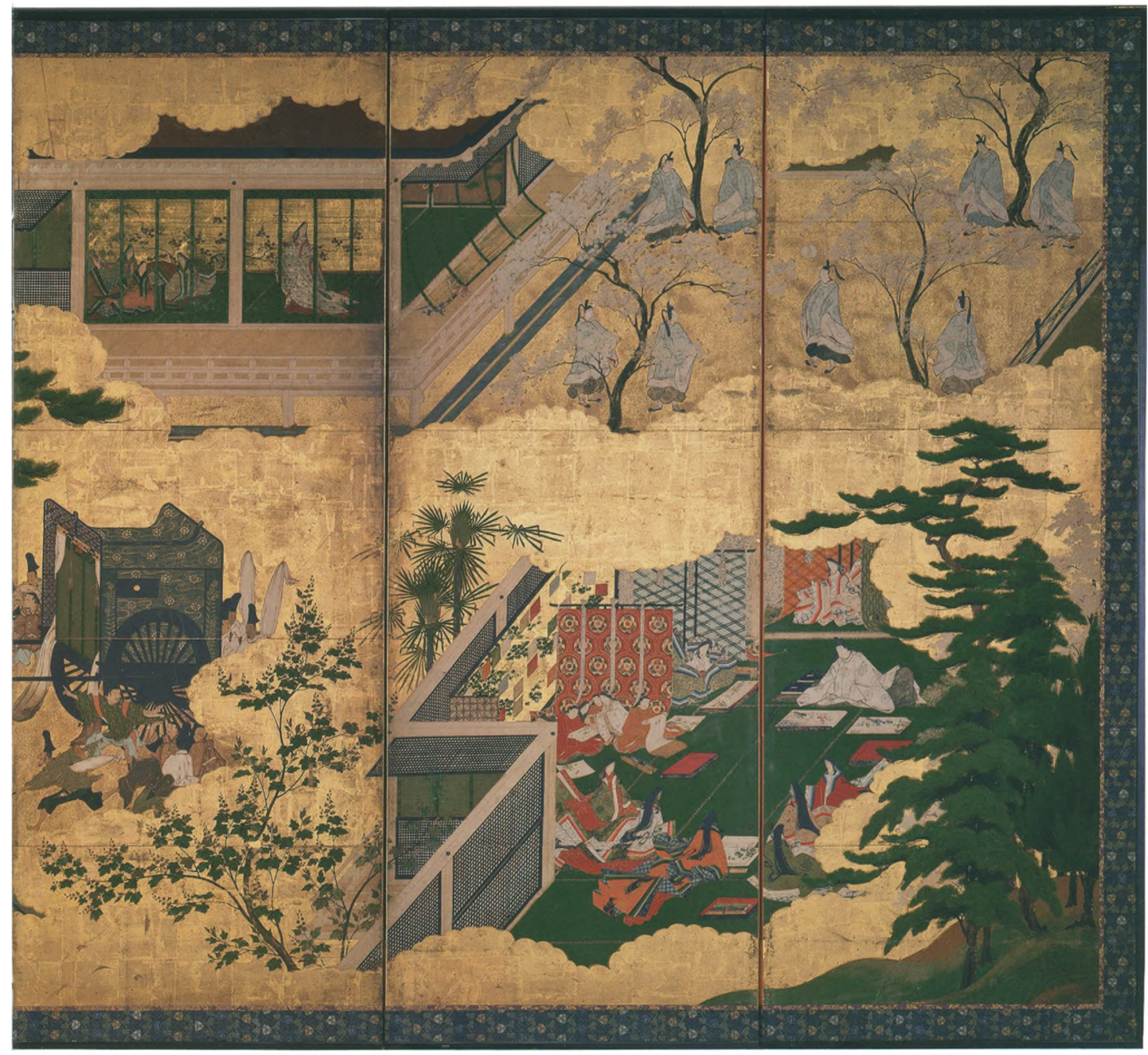


Figure 2

Utagawa Kunisada.

"Futaba no Ue", from

the series A rustic Genji

by a fraudulent

Murasaki (Nise

Murasaki inaka Cenji).

Ca. 1838. Oban.

Publisher: Tsuruya

Kiemon. Paulette and

Jack Lantz collection.

Photograph by Steve

Crise, Los Angeles.

Marks 2012, G297-005

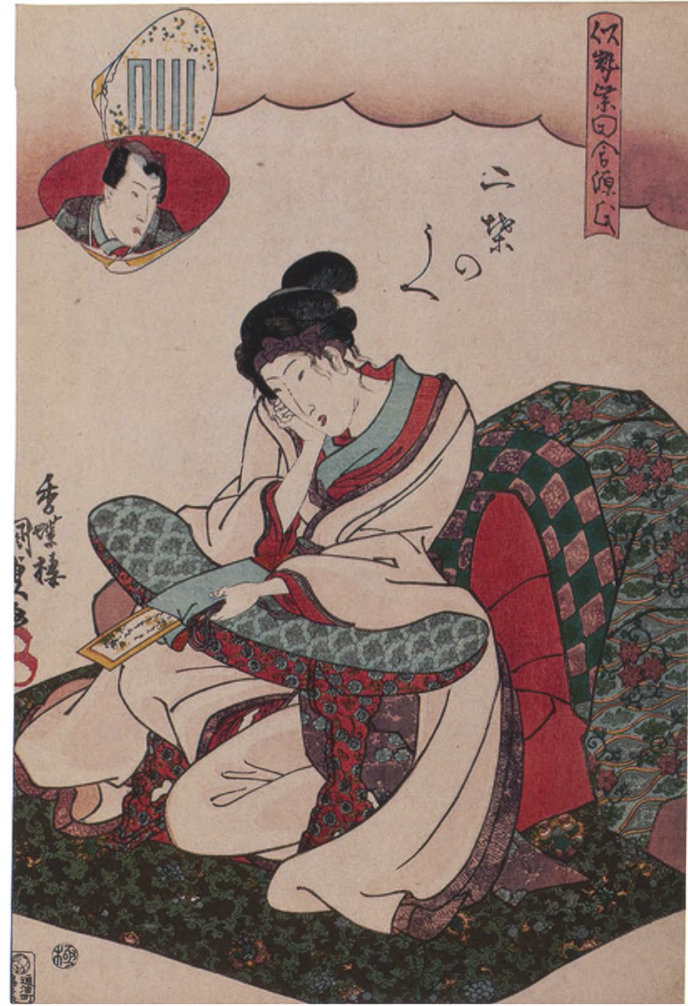

Figure 3 >> Isoda Koryusai. "The Imperial Progress" (Miyuki), from the series Cenji in elegant disguise (Furyu yatsushi Cenji). Ca. 1770-72. Chuban. Publisher unknown. National Diet Library, Tokyo. Marks 2012, Co16-29

through the title or theme. The fifty-four sheets of Genji (Genji gojuyonmai no uchi) by Nishimura Shigenaga (ca. 1697-1756) and Torii Kiyomasu II (1706-63), produced during the first half of the 1730s, is probably the earliest series with designs for each of the fifty-four chapters of the novel. ${ }^{2}$ These prints adopt a more or less standardized set of recognizable scenes that were originally drawn by Tosa painters using techniques characteristic of Yamato-e, a style of nativist painting. Tosa-school artists were patronized by the aristocracy, which favoured poetic depictions of Genji employing simplified renditions of facial features (hikime kagibana; literally, "slit eyes, hooked nose") and compositional devices such as roofless buildings (fukinuki yatai).

By the mid-18th century, artists and publishers had begun using the fifty-four chapters of Genji as a device for print series illustrating beautiful women, as can be seen in Genji in elegant disguise (Furyu yatsushi Genji) by Isoda Koryusai (1735-90). Each sheet juxtaposes one or more generic beauties with a specific chapter, from which a representative poem is also inscribed on the print (fig. 3). In this particular case, two beautiful women carrying umbrellas to protect them from the snow are paired with the verse: "O do come today and favour again a haunt where pheasants once rose that time on Mount Oshio, over the slopes deep in snow." ${ }^{3}$

In response to the interest raised by A rustic Genji, the use of the classical Genji as a series device was expanded and also applied to the depiction of warriors and actors, two other main subjects in the woodblock-print repertory. Up to the mid-1880s, almost 500 prints pairing Genji with other subjects were released. 


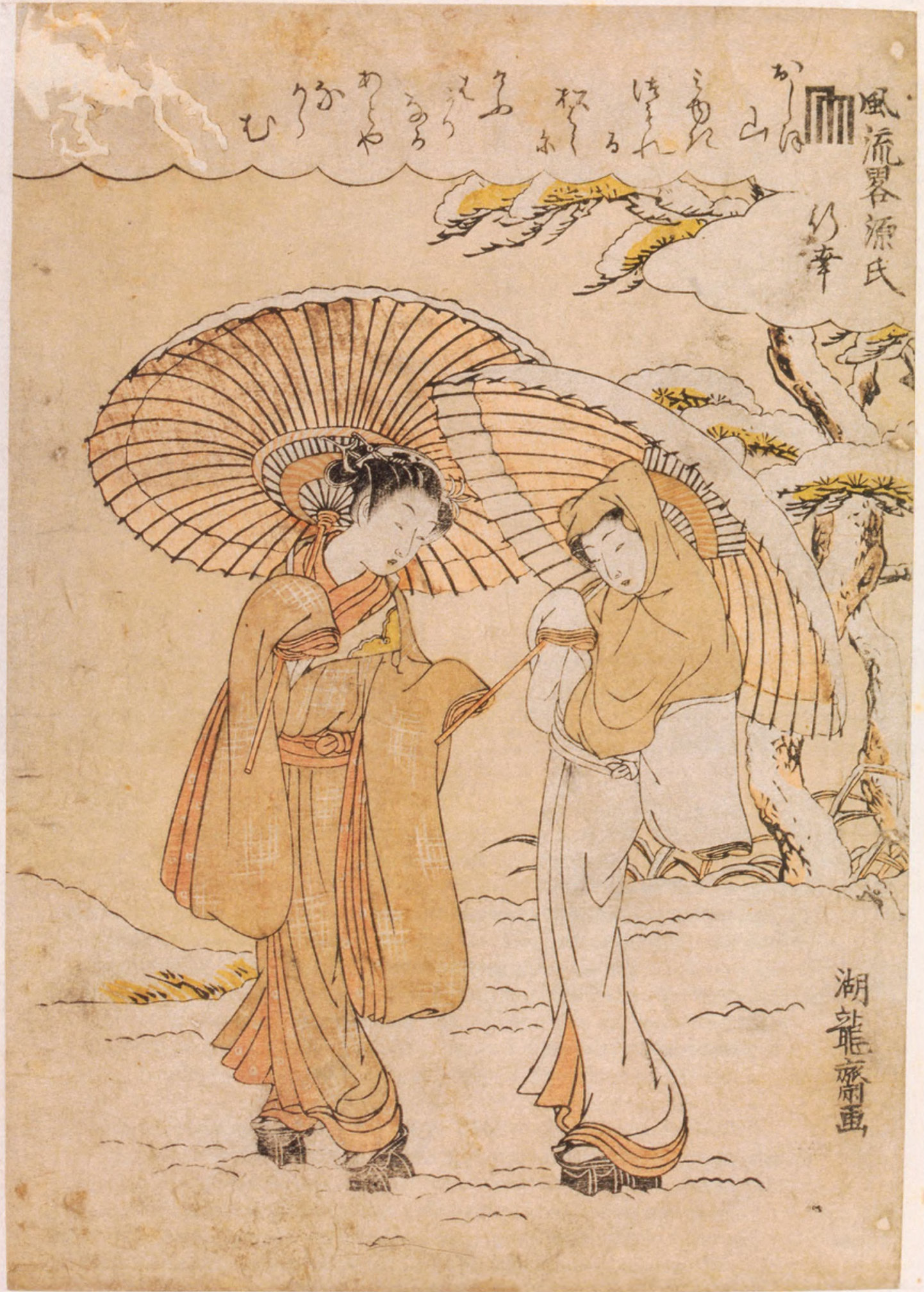


Figure 4 (a, b and c)

Utagawa Kunisada. "Spring," from the series Copied

pictures of graceful eastern figures (Yasa sugata azuma no

utsushi-e). 1849-51. Oban triptych. Publisher: Sanoya

Kihei. Paulette and Jack Lantz collection. Photograph by

Steve Crise, Los Angeles. Marks 2012, G315-01

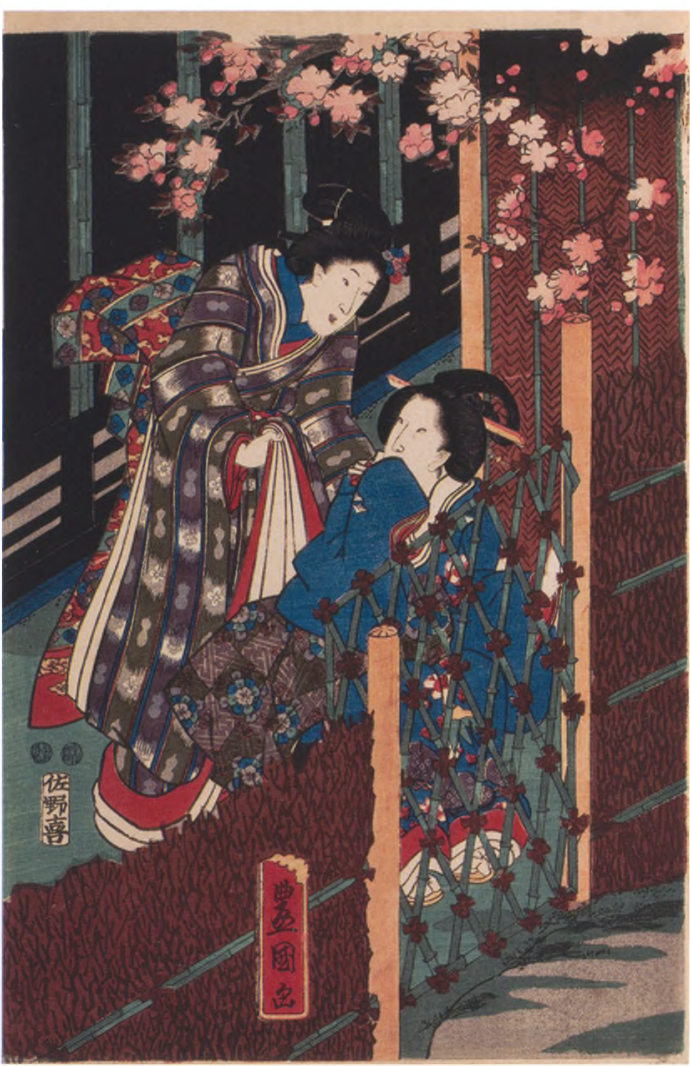

\section{Prints of 'A rustic Genji'}

Comprising well over 600 images, half of the designs related to A rustic Genji are by the illustrator of the original serial novel, Kunisada. His output as an individual artist was never equalled, not even by that of his pupil and son-inlaw Utagawa Kunisada II (1823-80), who designed over three hundred prints. There is again a large gap between Kunisada II and the third most prolific artist of Genji prints, Utagawa Hiroshige II (1826-69), with 75 designs to his name. He only occupies this position however, because of the many collaborative works with Kunisada and Kunisada II in which Hiroshige II furnished the complementing element, mostly a scenic background.

The vast majority of Rustic Genji prints are triptychs, which became the predominant format for this genre through Kunisada's work in the early $1840 \mathrm{~s}$. The craze peaked in the $1850 \mathrm{~s}$ and continued into the $1860 \mathrm{~s}$, fuelled by designs created by Utagawa-school artists. During the late 1860 s, the number of original designs dropped and after 1871 new Genji prints appeared only sporadically until 1897-98 when Utagawa Kunisada III (1848-1920) released the series Fifty-four chapters of Genji (Genji gojuyojo). ${ }^{4}$ 

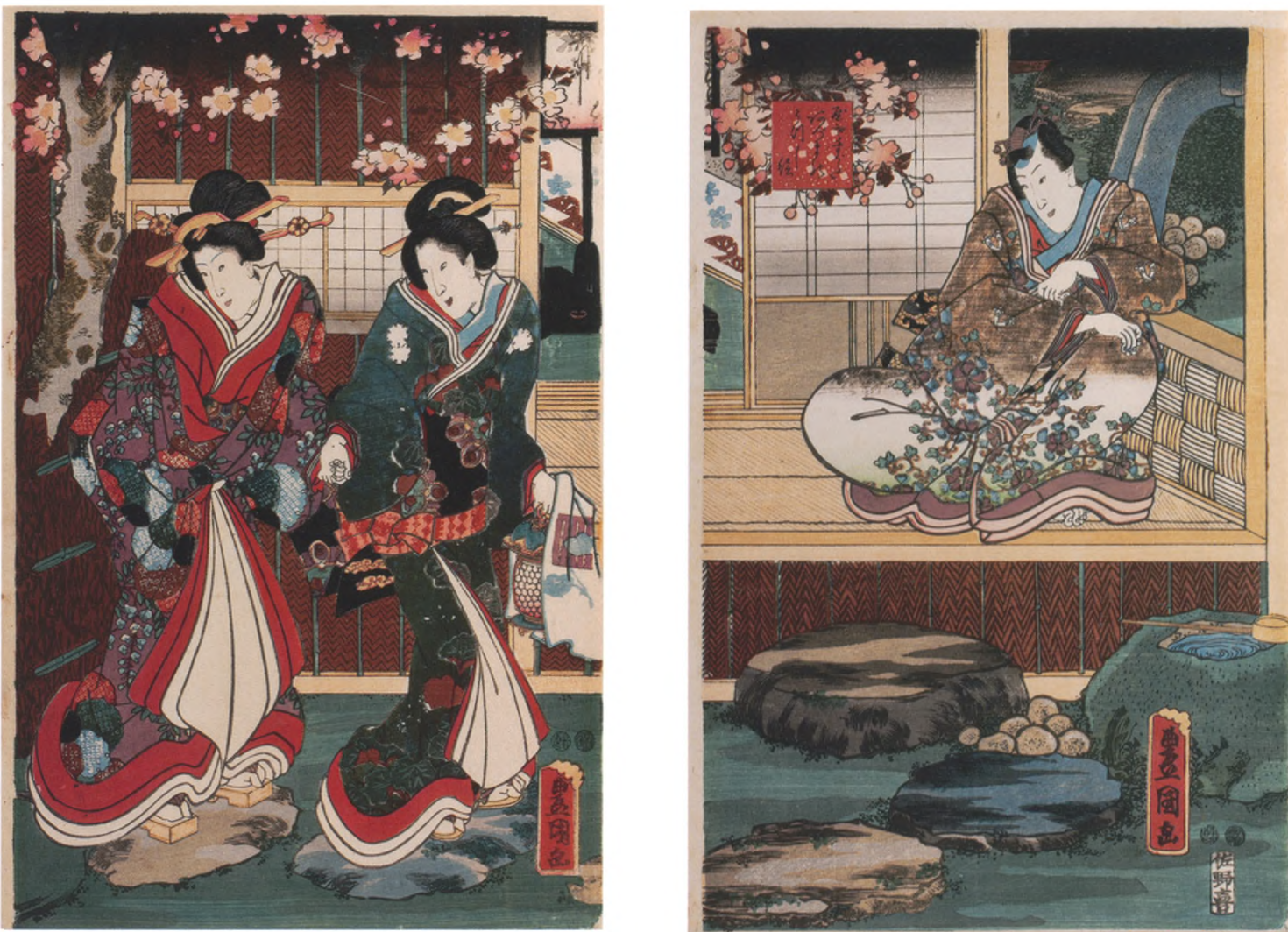

conformity was not necessarily due to a lack of creativity. Rather, it was probably the result of the designers' expectations, based on past experience, that familiar motifs, i.e. those drawn from the book illustrations, would enjoy commercial success. Clients were apparently attracted by conservative representations of well-known characters and scenes, but in a different format. Readers of $A$ rustic Genji were used to seeing two facing pages approximately 17.5 centimetres high and 23.5 centimetres wide. Only the covers of the booklets were produced in colour; the inside pages were monochrome. On the other hand, oban triptychs are approximately 39 centimetres high and 81 centimetres wide, and are printed in an impressivet range of brilliant colours.

As the designer of the original Rustic Genji illustrations, Kunisada had an unmatched familiarity with the imagery of the plot, which he adapted in countless numbers of marketable solo designs in varying formats, predominantly oban. The triptych "Spring" from the series Copied pictures of graceful eastern figures (Yasa sugata azuma no utsushi-e) was produced between 1849 and 1851 (fig. 4) and is based on an illustration in chapter nine that was first issued in 1833 (fig. 5). The double-page illustration is featured on the right and middle sheets, but the left sheet of the triptych is a

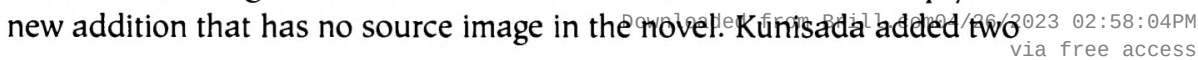




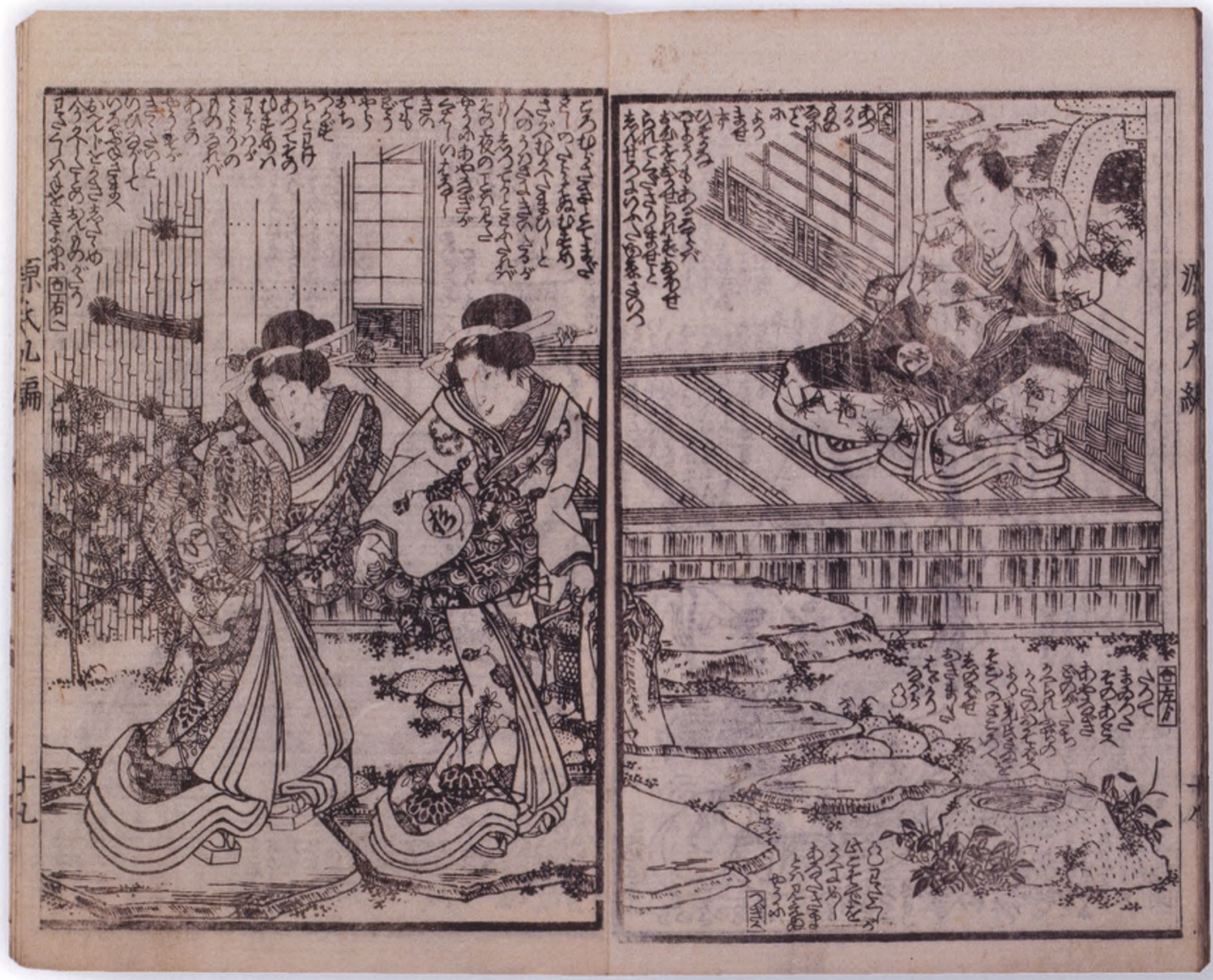

Figure 5

Utagawa Kunisada. A rustic Cenji by a fraudulent Murasaki

(Nise Murasaki inaka Genji), chap. 9, p. 18/19. 1833.

Ca. $17.5 \times 23.5 \mathrm{~cm}$. Paulette and Jack Lantz collection.

Photograph by Steve Crise, Los Angeles 


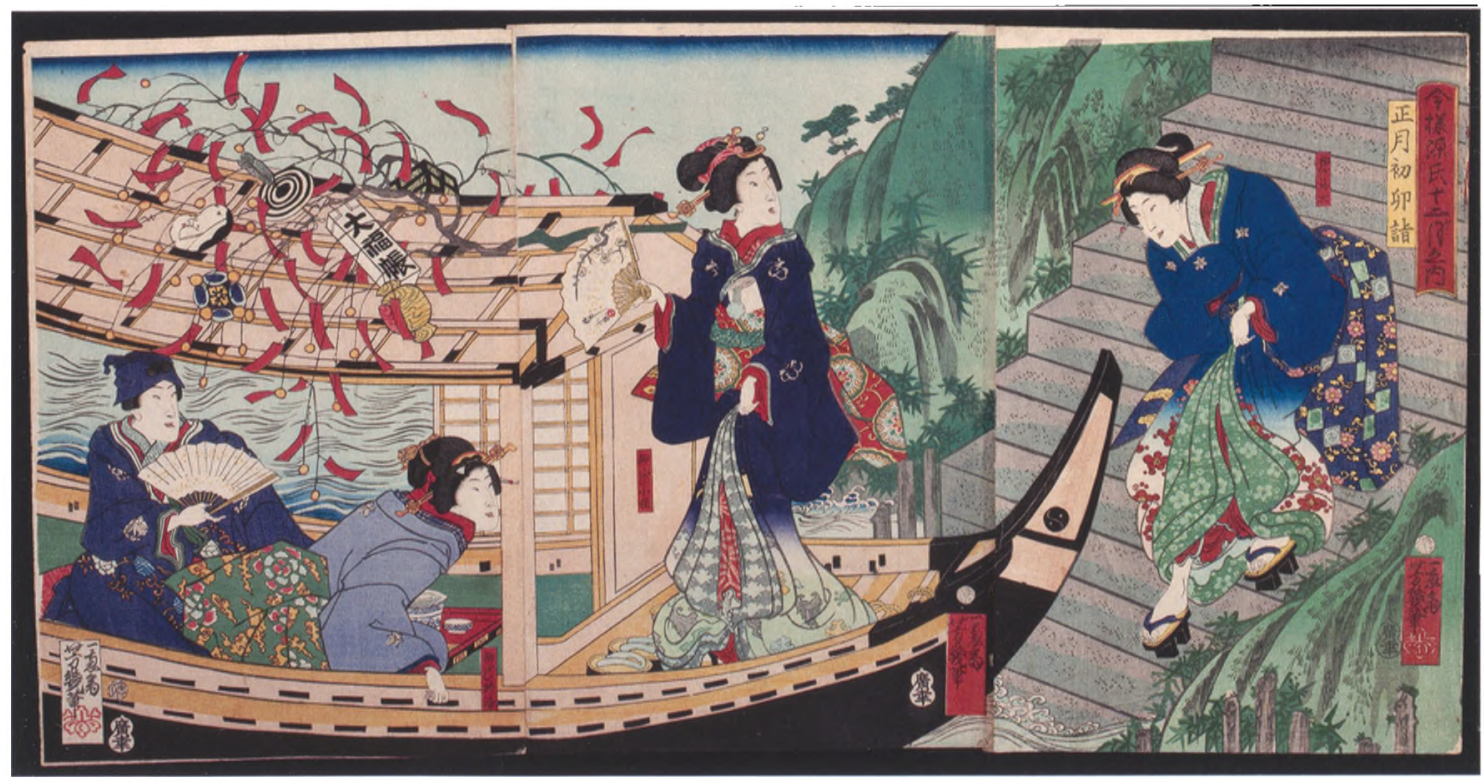

beautiful women and inserted cherry blossom over all three sheets to give a seasonal marker for spring.

Over time, the market for Genji prints developed further and a vogue for fresh designs that were not predominantly based on the book illustrations emerged (fig. 6). Artists began to create completely new images inspired by, but unrelated to A rustic Genji by portraying the story's protagonists, above all Mitsuuji, in hitherto unseen situations. If they are not familiar with the original book, viewers today are unlikely to distinguish these unrelated, imaginative depictions from prints based on the book illustrations, unless they include modern accretions such as telegraph poles and coaches, which were introduced to Japan after the publication of $A$ rustic Genji. Utagawa Yoshiiku (1833-1904), for example, depicts our protagonist during the New Year festivities sitting in a roofed boat, upon which several auspicious objects, including an arrow hitting a target (atariya), an account book (daifukucho), and an Otafuku mask are placed; a scene that we will not find in the original serial novel.

The overwhelming popularity of $A$ rustic Genji led to a re-evaluation of the original Genji through the lens of its 19th centuryoadaptation. Consequently, 02:58:04PM 


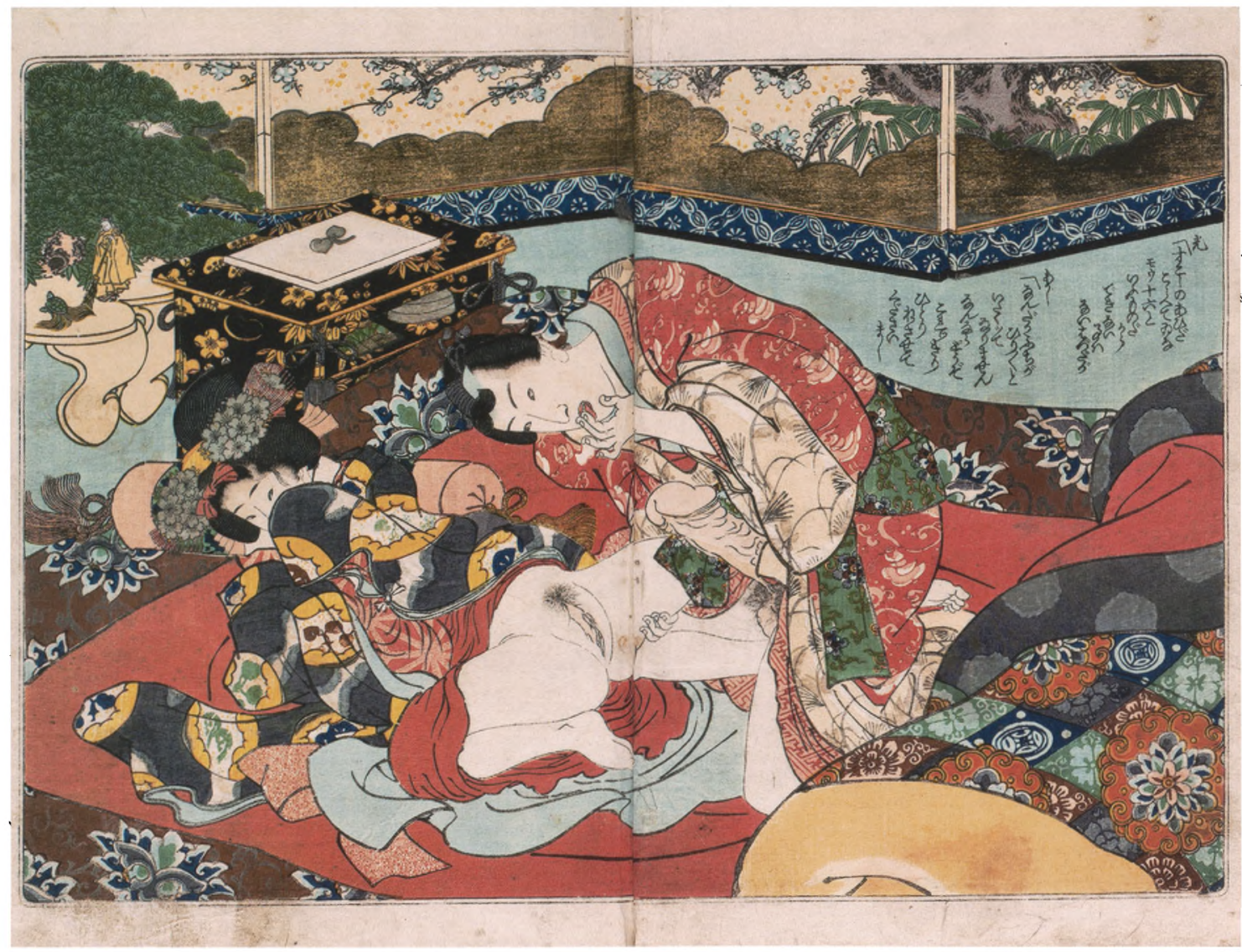

Figure 7

Utagawa Kunisada.

Realistic portraits of

Genji (Sho utsushi aioi

Cenji), vol. 3, p. 4/5.

1851. Ohon. Paulette

and Jack Lantz

collection. Photograph

by Steve Crise, Los

Angeles. Marks 2012,

So 48 the distinction between a print linked to Genji and a print related to A rustic Genji became ambiguous, and even arbitrary. Genji prints in general can be identified by a canon of specific terminology that was often used in the titles. The name "Genji" can relate to either Genji or A rustic Genji or both and it is found on one third of all Genji prints. Terms that clearly refer to A rustic Genji like inaka ("rustic"), nise ("fraudulent"), or Mitsuuji were rarely used.

Not all prints bear titles, which makes it necessary to look for other markers in order to classify a design as a Genji print. As a rule, Genji prints include an elegant, smartly dressed man accompanied by women. A distinctive topknot shaped like a shrimp tail (ebichasen) generally indicates that the male protagonist is Mitsuuji and not Prince Genji. However, this does not necessarily mean that all male protagonists without this hairstyle are therefore Prince Genji. In some cases, an elegant man is missing altogether, which makes the identification of such a design as a Genji print difficult. However, the presence of familiar scenes that can be found in the book illustrations indicate a clear relation to $A$ rustic Genji.

There were no restrictions on the types of designs based on the Genji theme, and this was even extended to explicit erotic wersions predominantly issued $02: 58: 04 \mathrm{PM}$ 
in book format (fig. 7). Like Prince Genji, Mitsuuji is involved in a succession of romantic entanglements, making him and the plot of the novel ideal subjects for sexually graphic adaptations. Kunisada, the most prolific and sought-after designer at that time, also dominated the field of erotic Genji books with at least eight. ${ }^{5}$

While some other illustrated books of the Edo period (1603-1868) also inspired insular cases of print designs based on their plots and characters, no other work like A rustic Genji had so much appeal and influence that it spurred an entirely new print genre. Whether as Mitsuuji or Prince Genji, the strikingly handsome male protagonist, depicted together with one or more beautiful women in familiar scenes derived from the novel or in freshly conceived settings, proved to be tremendously popular.

- Dr. Andreas Marks is the Director and Chief Curator of the Clark Center for Japanese Art and Culture in California. He has a master's degree in East Asian Art History from the University of Bonn, and a Ph.D. from Leiden University. A specialist in Japanese prints, he is the author of Japanese woodblock prints: Artists, publishers and masterworks, 1680-1900, and Publishers of Japanese prints: A compendium. His newest book, Genji's world in Japanese woodblock prints, was published in October 2012 (Hotei Publishing).

\section{Bibliography}

Michael Emmerich, 'A rustic Genji by a fraudulent Murasaki: A sense of the story' in: Marks, Genji's World in Japanese Woodblock Prints, pp. 18-21.

Andreas Marks, Genji's world in Japanese woodblock prints: From the Paulette and Jack Lantz collection. With contributions by Bruce A. Coats, Michael Emmerich, Susanne Formanek, Sepp Linhart, and Rhiannon Paget. Leiden: Hotei Publishing; Scripps College, Claremont, 2012.

Shikibu Murasaki, The tale of Genji. Translated by Royall Tyler. Penguin, Princeton, N.J., 2003. [Originally published by Viking, New York, 2001]

Rhiannon Paget, 'Erotic Genji Fantasies', in: Marks, Genji's World in Japanese Woodblock Prints,

\section{Notes}

1. For an introduction to the plot, see Emmerich 2012: pp. 18-21.

2. Marks 2012: G546.

3. Translation from Murasaki 2003, p. 500.

4. See Marks 2012: cat. nos. 274-5 (G425) and nos. 50-103 (G317).

5. For a detailed discussion of this subject, see Paget 2012: pp. 54-67. 

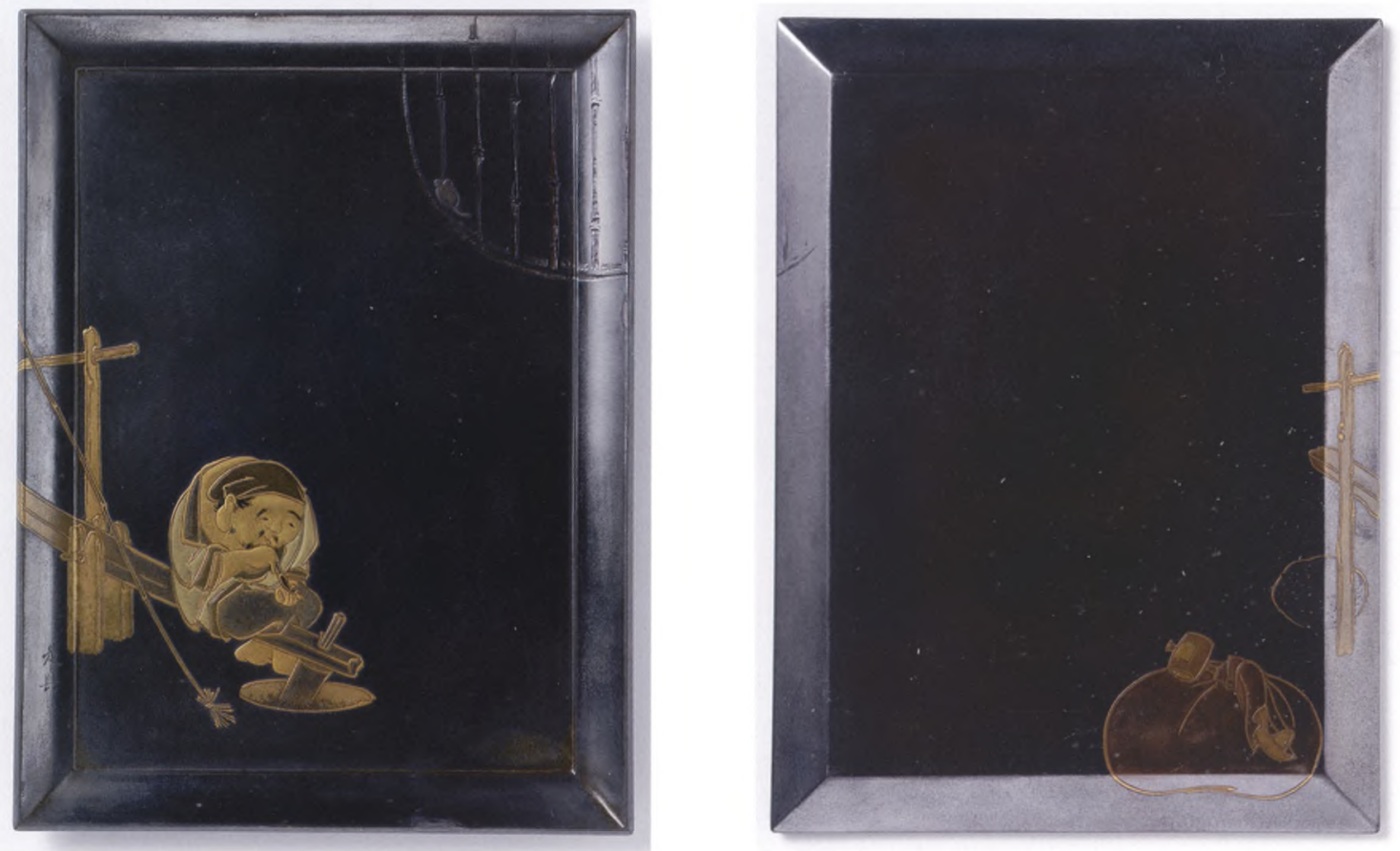

\section{Afbeelding 1, 2}

en omslag (detail)

Voor-en achterkant

van blaadje, lakwerk,

I. $9,5 \mathrm{~cm}$., Japan, $1850-$

1890, Rijksmuseum,

bruikleen Vereniging

van Vrienden der Azia-

tische Kunst, legaat

H.K. Westendorp,

inv.nr. AK-MAK-697. 